Elsevier required licence: (C) 2016. This manuscript version is made available under the CC-BY-NC-ND 4.0 license http://creativecommons.org/licenses/by-nc-nd/4.0/ 


\section{Concentrating underground brine by FO process: Influence \\ 2 of membrane types and spacer on membrane scaling}

3 Gang Chen ${ }^{1,2}$, Zhouwei Wang ${ }^{1}$, Xue-Mei Li*1, Jianfeng Song ${ }^{1,3}$, Baolong Zhao ${ }^{1}$,

6 'Laboratory for Membrane Materials and Separation Technology, Shanghai Advanced

7 Research Institute, Chinese Academy of Sciences, Shanghai, 201210, China

$8 \quad{ }^{2}$ State Key Laboratory for Modification of Chemical Fibers and Polymer Materials,

9

Corresponding authors: het@sari.ac.cn,afmgroup@126.com Tel: +86-21-20325162; Fax: 0086-21-20350925

\section{To be submitted to Chemical Engineering Journal

${ }^{5}$ Centre for Technology in Water and Wastewater, School of Civil and Environmental Engineering, University of Technology, Sydney (UTS), P.O. Box 123, 15 Broadway, NSW 2007, Australia

6


24 - FO process could be suitable for the concentration of underground brine.

25 - Membrane scaling occurred due to inorganic crystallization.

26

- $\quad$ The spacer in the FO cell enhanced membrane scaling.

27

- $\quad$ TFC membrane with rougher surface was prone to be scaled.

28

29

30 


\section{Abstract}

Forward osmosis (FO) is a low energy process when recovery of the draw solutes is not necessary. This study focused on the performance of the FO process for concentrating underground brine (UGB) with saturated sodium chloride as draw solution (DS) using two membranes: commercialized flat sheet cellulose triacetate (CTA) membrane and tailor-made thin film composite (TFC) FO membrane. Energy dispersive X-ray spectroscopy (EDS) and powder X-ray diffractometry (XRD) analysis indicate that, majority of the scaling components were calcium sulfate and sodium chloride crystals formed both through surface and bulk crystallization. The spacer in the FO test cell also promoted scaling. Without spacer, a sharp flux decline of TFC membrane occurred at a higher concentration factor while no sharp flux drop was observed for CTA membrane. It was hypothesized that the rough TFC membrane surface may initiate nucleation and aggregation of the crystals in the active surface, and eventually resulting in scaling.

Keywords: forward osmosis; underground brine; scaling; surface morphology; brine concentration 


\section{Introduction}

Forward osmosis (FO) is an osmotically driven membrane process, where the chemical potential difference acts as the driving force for the transfer of water (or any solvent) across a semi-permeable membrane [1]. As a result of water transfer across the membrane, the feed solution (FS, with a lower osmotic pressure, i.e. a higher chemical potential) becomes concentrated, and the draw solution (DS) diluted [1, 2]. This spontaneous natural process has been reported for various potential applications such as treatment of brackish water [3, 4], liquid food concentration [5], medical and pharmaceutical applications [6], treatment of produced waters from oil and gas exploitation industry $[2,7]$, desalination for irrigation [8], and power generation [9, 10]. In comparison to $\mathrm{RO}$ and nanofiltration processes, FO process alone is a low energy process that can tolerate a wider range of feed water salinity or total dissolved solids (TDS) [11-13]. But the recovery of the draw solutes from the diluted draw solution is energetically unfavorable [14], which limits the applications of the FO process. However, when the recovery of draw solutes is not necessary, FO process may become energetically favorable or even potentially carbon neutral. The exploration of such applications is the key for the success of FO.

Underground brine (UGB) is often found in sedimentation basins, and usually contains a high concentration of salts. As an important natural source, UGB can be used for the production of various inorganic chemicals including $\mathrm{Na}_{2} \mathrm{CO}_{3}$. [15]. The salinity of UGB is in general much higher than seawater. Evaporation ponds have been used to concentrate the UGB up to the saturation point to obtain crude salts. This 
conventional dewatering process is very slow and characterized by a very large footprint. Also, to harvest the crude salts is energy intensive because the salt crystals have to be collected over a very large area and transported to the central treatment points. The salts are then dissolved in fresh water as a saturated solution and supplied to the refining production line for the production of $\mathrm{Na}_{2} \mathrm{CO}_{3}$ and others. Considering that in the evaporation process water has to be removed while in the dissolution step a large quantity of fresh water has to be supplied, a new process would be desirable that can utilize the removed water for the desalination of crude salts. Based on the process characteristics, FO may become an energy-efficient process to concentrate the UGB in place of evaporation pond using the crude salts as DS, where FO can both intensify the evaporation process, and reduce fresh water demand for the crude salts dissolution. This process has not been described in literature, the process characteristics, especially membrane scaling might be a significant problem, which needs systematic investigation.

The aim of this work is therefore to investigate the performances of the FO process in concentrating UGB, using both tailor-made flat sheet polyamide thin film composite (TFC) FO membrane and the commercialized cellulose triacetate (CTA) FO membranes in terms of water flux behavior and membrane scaling. The results from this study is expected to provide enhanced understanding of the likely challenges and issues for the application of FO process for the treatment of high salinity water by FO process. 


\section{Materials and methods}

\subsection{Chemicals and Membranes}

$\mathrm{NaCl}$ (AR grade), triethyl amine (TEA, AR grade), and camphorsulfonicacid (CSA, AR grade), polyethylene glycol (PEG, Mw 400 Da.) and dimethyl acetamide (DMAc) were supplied by Sinopharm Chemical Reagent Co., Ltd. m-phenylnenediamine (MPD, 99\%) and trimesoyl chloride (TMC, 98\%) were supplied by Sigma (AR). The chemicals were used without further purification. Polysulfone (P-3500 NT) was purchased from Solvay (Shanghai, China). Sulfonated polyether ether ketone (SPEEK) was supplied by Shanghai Erane Tech. Co. Ltd, with a sulfonation degree of $64.4 \%$. Commercial CTA membranes were supplied by Hydration Technologies, Inc. (Albany, OR, USA). Natural UGB was kindly provided by Shandong Haihua Group Co., LTD. Deionized (DI) water was used wherever necessary for the experiments.

\subsection{Preparation of flat sheet TFC membranes}

\subsubsection{PSf support membrane}

PSf/SPEEK/PEG-400/DMAc (17.1/0.9/8 /73.6) was mixed in a dry three-neck flask at $65^{\circ} \mathrm{C}$ overnight till a clear solution was obtained. The polymer solution was filtered, de-aerated in an oven at $60{ }^{\circ} \mathrm{C}$ overnight, and cast on a dry glass plate at 150 $\mu \mathrm{m}$ by an automatic casting apparatus (Elcometer 4340, Elcometer Asia Pte. Ltd). The nascent cast was then immersed into a water bath $\left(30^{\circ} \mathrm{C}\right)$ for precipitation. Resulting PSf membrane was washed thoroughly and stored in DI water.

\subsubsection{Flat sheet TFC membrane}



by interfacial polymerization of MPD in the aqueous phase with TMC in hexane. The composition of aqueous phase was prepared according to previous studies [16] at a $\mathrm{pH}$ of 11.2. The top surface of the PSf membrane was dried with an air knife and brought into contact with aqueous phase for $2 \mathrm{~min}$. The excessive aqueous solution was decanted and the membrane surface was blown dry using a dry clean nitrogen gas stream. Afterwards, the membrane was brought into contact with an organic phase (TMC/hexane solution, $0.15 \mathrm{wt} \%$ ) for $1 \mathrm{~min}$. The membrane was then dried at ambient for $2 \mathrm{~min}$ and cured in an oven at $100{ }^{\circ} \mathrm{C}$ for $3 \mathrm{~min}$. The membranes were stored in DI water before further test.

\subsection{Pure water permeability and salt rejection of the FO membranes.}

rejection $\left(R_{S}\right)$, structural parameters $(S)$ of the membranes were characterized was obtained using a bench scale cross-flow RO test setup (Sterlitech Corporation) under a pressure of 10 bar. The salt rejection $\left(R_{s}\right)$ was determined based on conductivity of the permeate and feed solution $(1000 \mathrm{ppm} \mathrm{NaCl})$ at a flow velocity of $0.25 \mathrm{~m} / \mathrm{s}$ under pressure of 10 bar. $B$ was calculated based on equation (1). where $J_{w}{ }^{N a C l}$ is water flux of $\mathrm{NaCl}$ solution, $R_{s}$, is salt rejection, $k$ represents the mass transfer coefficient for the cross-flow cell, and was calculated from correlation for a rectangular cell geometry and laminar flow [18] 

diffusion $\left(K_{m}\right)$ and solute diffusivity $(D)$, and its relationship with the membrane tortuosity $(\tau)$, membrane thickness $\left(t_{s}\right)$, and membrane porosity $(\varepsilon)$ is given as follows:

$$
S=K_{m} D=\frac{t_{s} \tau}{\varepsilon}
$$

The resistance of support layer to solute diffusion $K_{m}$ is calculated (AL-FS mode: active layer against the feed solution) as follows:

$$
J_{v}=K_{m} \ln \left(\frac{A \pi_{\text {draw }}+B}{A \pi_{\text {feed }}+J_{v}+B}\right) \text { (AL-FS) }
$$

144 where $J_{v}$ refers to the water flux in the FO process using $0.5 \mathrm{M} \mathrm{NaCl}$ as DS and DI water as FS under the AL-FS mode of membrane orientation. $\pi_{\text {draw }}$ and $\pi_{\text {feed }}$ refer to the osmotic pressures of the DS and FS respectively, and here $\pi_{\text {feed }}$ was taken as zero because of DI water as feed for equation (3).

2.4 FO module configuration and lab-scale process experimental setup for

\section{concentrating UGB} enhance flow turbulence, reduce the external concentration polarization, and also provide support to the membrane. Before placing the FO membrane in the FO channels, a polymeric mesh spacer was inserted in the middle of the channel or in 
shown in Fig. 1 is the configuration means of polymeric mesh spacer in the FO membrane module. The effect of spacer on membrane fouling was investigated in detail (see section 3.5).

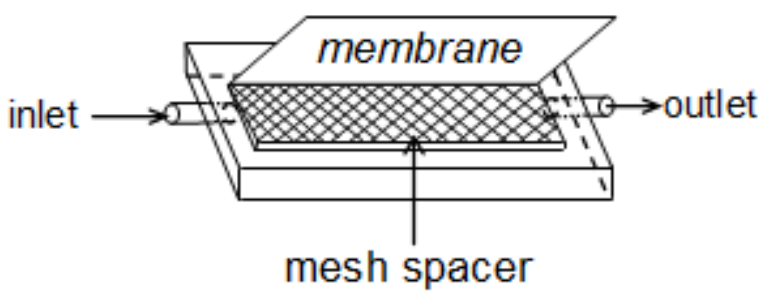

Fig. 1 Channel with the membrane and polymeric spacer in the FO membrane

module.

UGB was pre-filtered using a paper filter with a nominal pore size of $20 \mu \mathrm{m}$ to remove large particles. A saturated $\mathrm{NaCl}$ solution containing extra undissolved salt was used as the DS. Figure 2 shows the schematic layout of the lab-scale FO experimental setup used in this study. Two magnetically driven gear pumps (WT3000-1FA, Baoding Longer Precision Pump Co., Ltd) were used to control the flow velocities of both feed and DS. The flow velocity of both the feed and DS was set at $4.2 \mathrm{~cm} / \mathrm{s}$ for all the FO experiments with UGB. The temperature of both feed and DS was maintained at $20^{\circ} \mathrm{C}$. Membranes were tested in the AL-FS mode of membrane orientation with the active layer facing the feed solution. The weight change in the feed tank (initial volume of $1 \mathrm{~L}$ ) was tracked using a digital mass scale (CP4202C, Ohaus Corporation) connected with a computer for data recording. The FO water flux, $J_{v}$, was calculated based on the change in the volume of the feed tank $(\Delta V, \mathrm{~L})$ at unit time divided by the effective membrane surface area $(A)$, considering the density of water is $1.0 \mathrm{~kg} / \mathrm{L}$ : 


$$
J_{V}=\frac{\Delta V}{A \times t}
$$

The concentration factor $(\mathrm{CF})$ is defined as the ratio between the initial feed volume $\left(V_{0}\right)$ and the feed volume $\left(V_{t}\right)$ at time $t$, (which represents the increase in the feed concentration as the FO process was operated in a batch mode where both the DS and FS are recycled continuously) according to (5). Water recovery was calculated by dividing the overall volume of permeate (calculated from the total weight decrease of the feed solution) by initial volume of feed solution.

$$
C F=\frac{V_{0}}{V_{t}}
$$

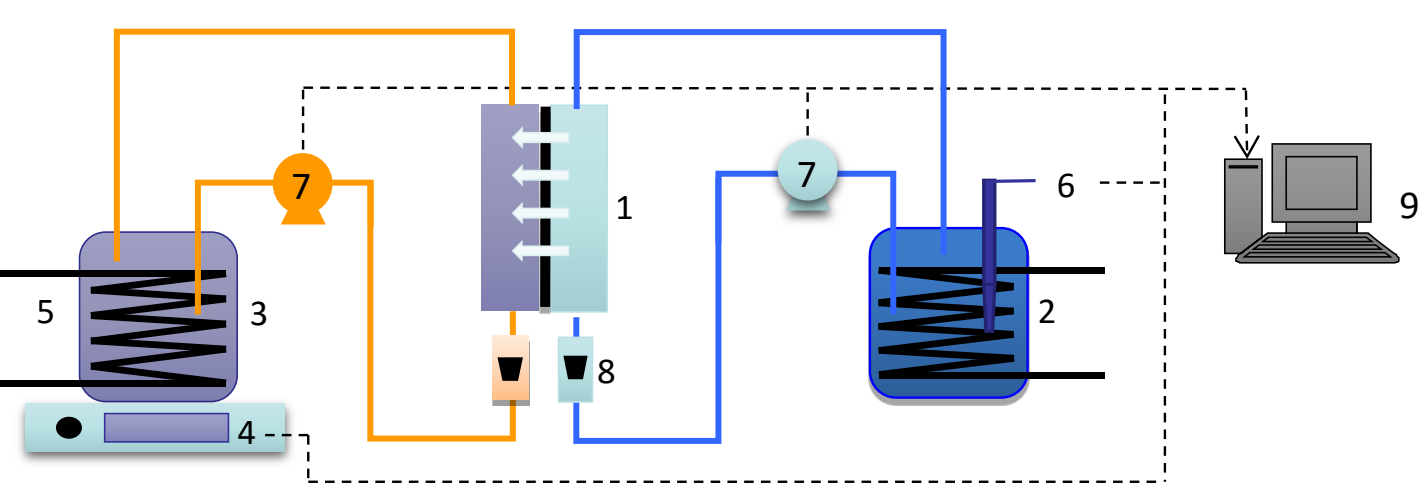

Fig. 2 Schematic of the forward osmosis test setup (1. membrane module; 2 . feed water tank; 3. draw solution tank; 4. balance; 5 . thermostatic bath; 6 . conductivity transmitter; 7. gear pump; 8. flow meter; 9. data collection system).

\subsection{Analytical methods}

Water quality parameters, including $\mathrm{pH}$, electric conductivity, turbidity, and total hardness, of UGB (before and after pretreatment) and product water were tested following standard methods [19]. Ion concentrations were determined by inductively coupled plasma-atomic emission spectroscopy (ICP-AES) (ICPE-9000, Shimadzu, 
Kyoto) and ion chromatography (LC20AT, Shimadzu, Kyoto), respectively. The ICP-AES utilizes the wavelength and intensity of electromagnetic emission to determine the concentration of each target element. Calibration was conducted prior to each batch of analysis. The linear regression coefficients $\left(R^{2}\right)$ for all calibration curves were greater than 0.99 . Foulants on the membrane surfaces were analyzed by scanning electron microscopy equipped with energy dispersive X-ray spectroscopy (EDS) (Hitachi S-4800, Japan). X-ray diffraction patterns were collected by X-ray powder diffractometry (Bruker D8 Advance).

\section{Results and discussion}

\subsection{Characteristics of the FO membranes}

SEM images of the virgin TFC and CTA membranes are shown in Fig. 3. The flat sheet TFC membrane shows a typical ridge-valley surface morphology (Fig. 3a) with sponge-like support structure and macrovoids close to the bottom surface (Fig. 3b). The CTA membrane (Fig. 3c) has a much smoother surface than the TFC membranes, reinforced by embedded woven mesh (Fig. 3d).

Other characteristics of the two membranes used in this study are listed in Table 1 . The pure water permeability of flat sheet TFC membrane was about $2.2 \mathrm{~L} /$ $\left(\mathrm{m}^{2} \cdot \mathrm{h} \cdot \mathrm{bar}\right)$ and $0.79 \mathrm{~L} /\left(\mathrm{m}^{2} \cdot \mathrm{h} \cdot \mathrm{bar}\right)$ for the CTA membrane, which agrees to literature results $[1,10]$. The observed FO flux, $J_{v}$, of the flat sheet TFC membrane was 10.5 $\mathrm{L} / \mathrm{m}^{2} \cdot \mathrm{h}$, about $20 \%$ higher than that of the CTA membrane. In terms of $\mathrm{NaCl}$ salt rejection, the flat sheet TFC FO membrane showed much higher $\mathrm{NaCl}$ salt rejection 
218 (98.8\%) than the CTA membrane (89\%), which indicated that the interfacial

219 polymerized TFC membranes are less permeable to salt. This is further supported by

220 the significantly lower $\mathrm{J}_{\mathrm{s}} / \mathrm{J}_{\mathrm{W}}$ values observed for TFC FO membrane than CTA

221 membrane. The $\mathrm{J}_{\mathrm{S}} / \mathrm{J}_{\mathrm{w}}$ value, termed as specific reverse solute flux measures the extent

222 of DS salt that is expected to be lost by reverse diffusion through the membrane

223 towards the FS which has both economic interest and the quality of feed concentrate.

224 Nevertheless, the TFC membrane has a twice as high a structural parameter, indicative

225 of higher degree of internal concentration polarization (ICP), as will be illustrated in

226 later paragraphs.
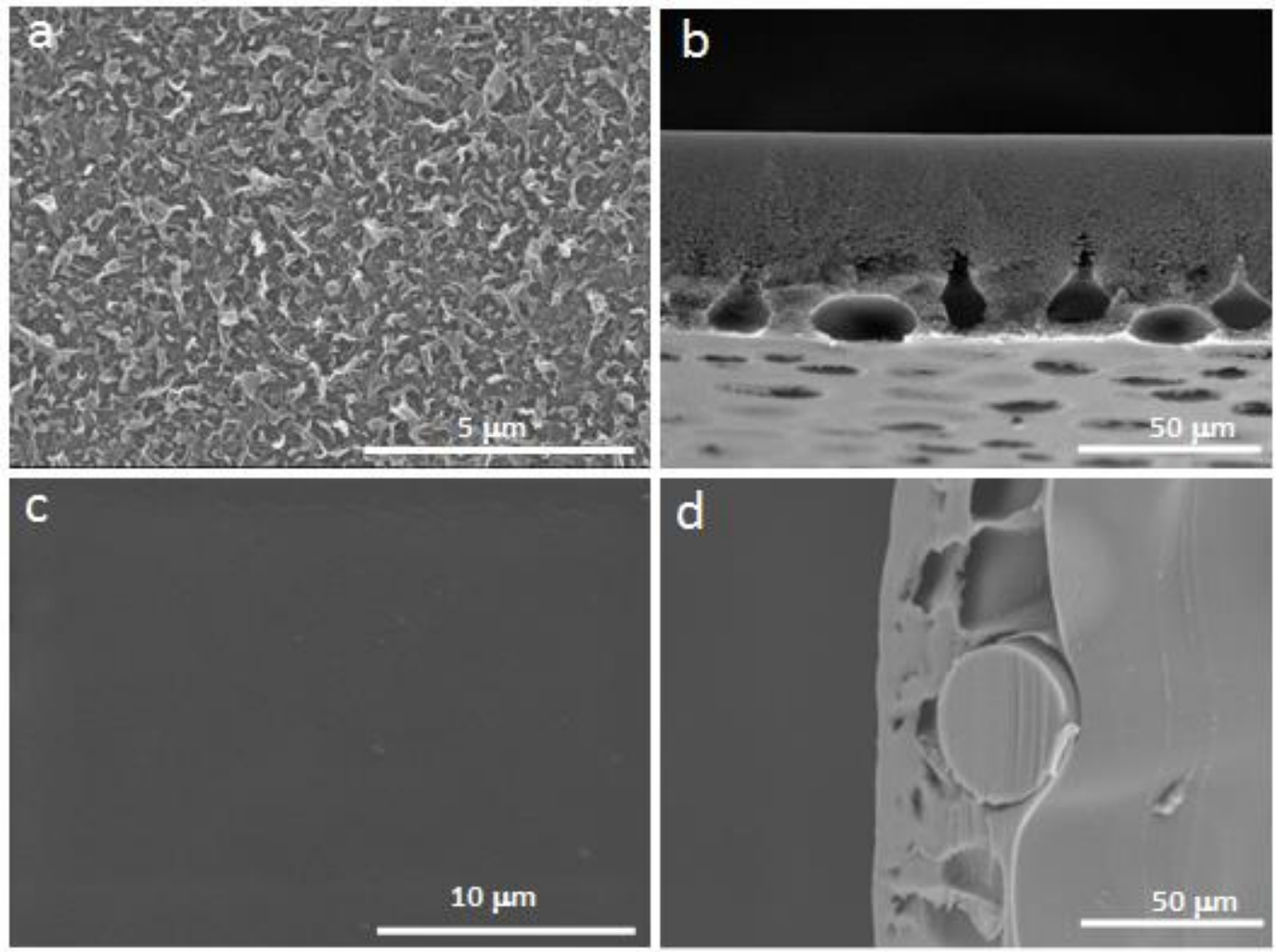

Fig. 3 SEM images of the FO membrane surfaces from the experiment. a) and b)

229 SEM images of top surface and cross-section of flat sheet TFC membrane; c) and d)

SEM images of the top and cross-section of flat sheet CTA membrane. 
232 Table 1 Properties of synthesized TFC FO membranes and commercial CTA

233 membranes

\begin{tabular}{|c|c|c|c|c|c|c|}
\hline FO membranes & $\begin{array}{l}\text { Pure water } \\
\text { permeability } \\
\left(\mathrm{L} / \mathrm{m}^{2} \cdot \mathrm{h} \cdot \mathrm{bar}\right)\end{array}$ & $\begin{array}{l}\mathrm{NaCl} \\
\text { rejection } \\
(\%)\end{array}$ & $\begin{array}{l}\text { Jv-FO mode } \\
\left(\mathrm{L} / \mathrm{m}^{2} \cdot \mathrm{h}\right)\end{array}$ & $\begin{array}{l}\mathrm{J}_{\mathrm{S}} / \mathrm{JV} \\
(\mathrm{g} / \mathrm{L})\end{array}$ & $\begin{array}{c}\text { B } \\
\left(\mathrm{L} / \mathrm{m}^{2} \cdot \mathrm{h}\right)\end{array}$ & $\begin{array}{c}S \\
(\mu \mathrm{m})\end{array}$ \\
\hline TFC & 2.25 & 98.8 & 10.5 & 0.44 & 0.2 & 799 \\
\hline CTA & 0.79 & 89 & 8.5 & 1.17 & 0.87 & 412 \\
\hline
\end{tabular}

\subsection{UGB water characteristics}

The UGB sample used in this study was obtained from coastal region of eastern

China. The detail characteristics of the UGB are presented in Table 2. The conductivity of UGB was $136 \mathrm{~ms} / \mathrm{cm}$, and the turbidity of 11.4 NTU. Sodium was the main cation with a concentration of $12.64 \mathrm{~g} / \mathrm{L}$ followed by magnesium $(9.33 \mathrm{~g} / \mathrm{L})$ and

240 calcium $(4.93 \mathrm{~g} / \mathrm{L})$. The major anions were chloride $(43.80 \mathrm{~g} / \mathrm{L})$ and sulfate $(9.88 \mathrm{~g} / \mathrm{L})$.

241 The TDS of the UGB was $120347 \mathrm{mg} / \mathrm{L}$ (or $120.35 \mathrm{~g} / \mathrm{L}$ ).

Table 2. Characteristics of pre-filtered UGB

\begin{tabular}{lc}
\hline Analytes & UGB \\
\hline Conductivity (mS/cm) & 136 \\
Turbidity (NTU) & 11.4 \\
$\mathrm{pH}$ & 7.2 \\
Sodium (mg/L) & 12640 \\
Calcium (mg/L) & 4930 \\
\hline
\end{tabular}




\begin{tabular}{lc}
\hline Potassium (mg/L) & 1064 \\
Magnesium (mg/L) & 9327 \\
Arsenic (mg/L) & 72.6 \\
Lead (mg/L) & 68.2 \\
Strontium (mg/L) & 63.4 \\
Chloride (mg/L) & 43800 \\
Sulfate (mg/L) & 9875.4 \\
Bicarbonate (mg/L) & 246.5 \\
Total ions (mg/L) & 120347 \\
\hline
\end{tabular}

\subsection{Performance of the FO process during UGB concentration}

Because of the relatively high salt content, UGB FO concentration was carried out using saturated $\mathrm{NaCl}$ solution with extra solids. Fig. 4 shows the water flux and recovery patterns for the two FO membranes as a function of concentration factor (CF) in the AL-FS mode. The initial flux of the CTA and TFC membrane was 9.0 and 8.2 $\mathrm{L} / \mathrm{m}^{2} \cdot \mathrm{h}$, respectively. Gradual water flux decline and recovery increase were observed

251 during the FO concentration process for both membranes. A flux transition was 252 observed in a CF range of 1.65 - 1.70 where a sharp flux decline was observed and 253 subsequently the water flux turned to nearly zero at about CF of 1.8. It was observed 254 that solution appeared highly turbid at the flux transition point, indicating that the 255 solution might be close to crystallization. Similar results phenomenon was reported by 256 other studies [20]. The water recovery of TFC and CTA membranes at the CF of 1.8 and 1.9 is $52.8 \%$ and $56.5 \%$, respectively. 
line with the flux difference as shown in Table 1, where a higher water flux was expected for the TFC membrane other than the CTA membrane. However, this is not surprising when we examine the structural parameter of the two membranes. The TFC membranes has shown a twice as high a $\mathrm{S}$ value as the CTA membranes, indicating that it will suffer severe dilutive ICP in the support layer. The degree of ICP is directly related to the solution concentration $[21,22]$, where higher concentration suffers more seriously. The lower initial flux of the TFC membrane is thus ascribed to the higher structural parameter and consequently higher degree of ICP than the CTA membrane. The gradual flux decline was expected because of the gradual increase in the feed concentration due to the concentration of the feed during the continuous FO operation process, leading to decreased osmotic driving force across the membrane. With the increase of concentration factor, the appearance of flux transition was interesting to note. The transition in the FO water flux for TFC membrane occurred at $\mathrm{CF}$ of 1.65 following which the water flux dropped to zero at CF of about 1.8. While for the CTA 273 membrane, the transition started at a CF of 1.7 reaching zero flux at CF 2.0. As noted above, the flux transition was visually linked to the turbidity of the feed streams.

275 Therefore, this flux transition is most probably caused by the saturation/crystallization of the salts in the feed streams. After dismantling the membrane test cell, a lot of

277 crystals are found on the spacer mesh as shown in Fig 5. In addition, crystals were also found on the membrane surface, which are shown in Fig 6. These observations confirm that the flux transition is caused by the crystallization and scaling of the membranes. 
CTA membrane indicates that, crystallization with TFC membrane occurs at low CF than with the CTA membrane. This difference might be caused by the different surface morphology of the membranes. More specifically, it is likely that the rougher surface of the TFC membranes provided more surface area and stronger adhesion force for the crystals to aggregate than a smooth one, similar to the colloidal fouling formation[23]. TFC membranes.

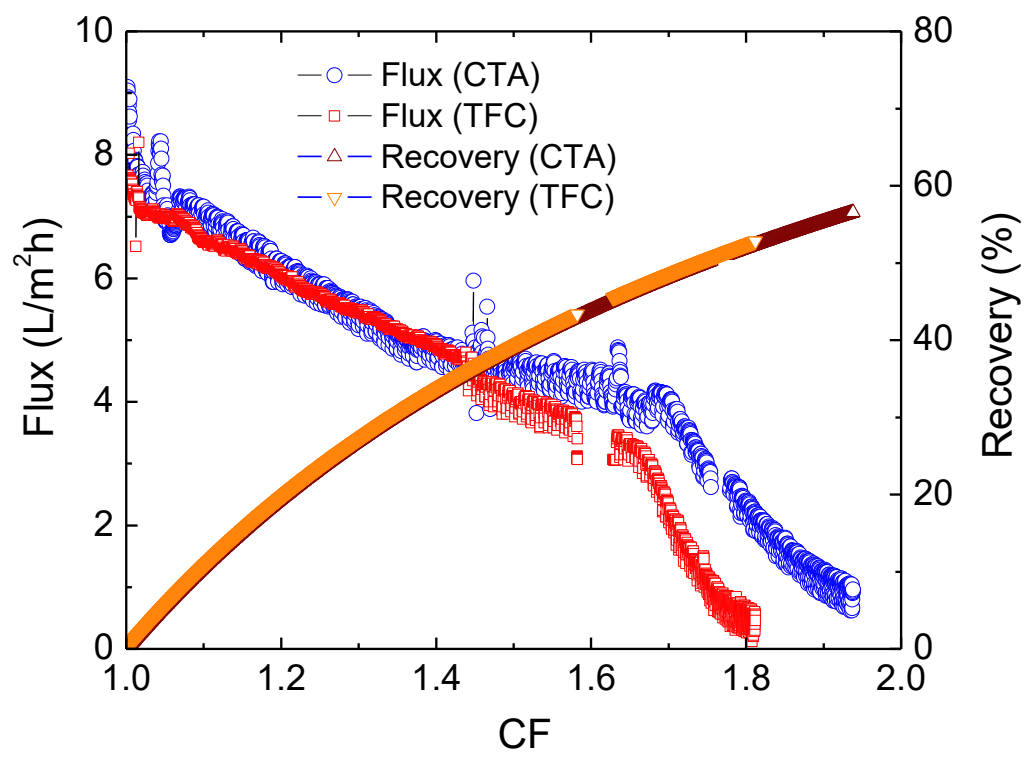

291 Fig. 4 Water flux and recovery patterns of flat CTA and TFC FO membranes against

292 concentration ratio (UGB and saturated sodium chloride were used as the feed and draw solution, respectively; experiments were conducted under temperature of $20 \pm$

$2941{ }^{\circ} \mathrm{C}$, the flow velocity and Reynolds number for both feed and DS were maintained at 
(a)

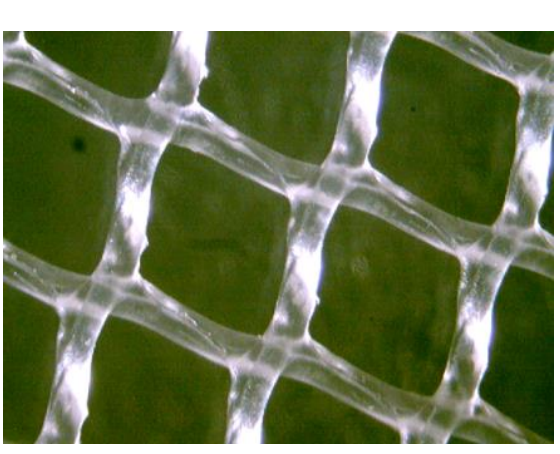

(b)

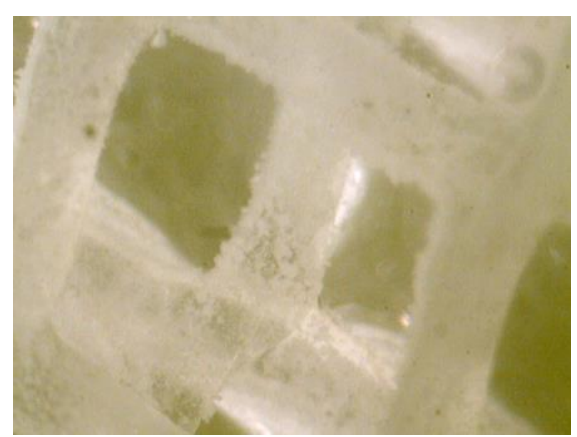

Fig. 5 Optical photographs of the mesh spacer before (a) and after (b) UGB FO

concentration (UGB and saturated $\mathrm{NaCl}$ solution were used as feed and draw solution, respectively; experiments were conducted under temperature of $20 \pm 1^{\circ} \mathrm{C}$ and flow velocities of feed and draw solution were maintained at $4.2 \mathrm{~cm} / \mathrm{s}$ )

\subsection{Analysis of the crystals}

Fig. $3 \mathrm{c}$ shows the fresh clean CTA membranes surface characterized by a smooth top surface however, for the used membrane, significant amounts of deposits in the form of single crystals and crystal aggregates, sporadically appeared in the fouled membrane surface (Fig. 6b). For the flat sheet TFC membrane, a typical ridge and valley surface morphology was observed for the clean membranes (Fig. 6c), however, for the used membrane, piles of deposits were observed after the FO process (Fig. 6d). The crystals were observed to exist in various shapes such as needle-like, parallelopiped, and irregular. Similar crystals deposition has been reported in other studies before [24, 25]. More crystal deposits were found for the flat sheet TFC membrane than the CTA membrane, probably indicating, TFC membrane is slightly more prone to scaling. 

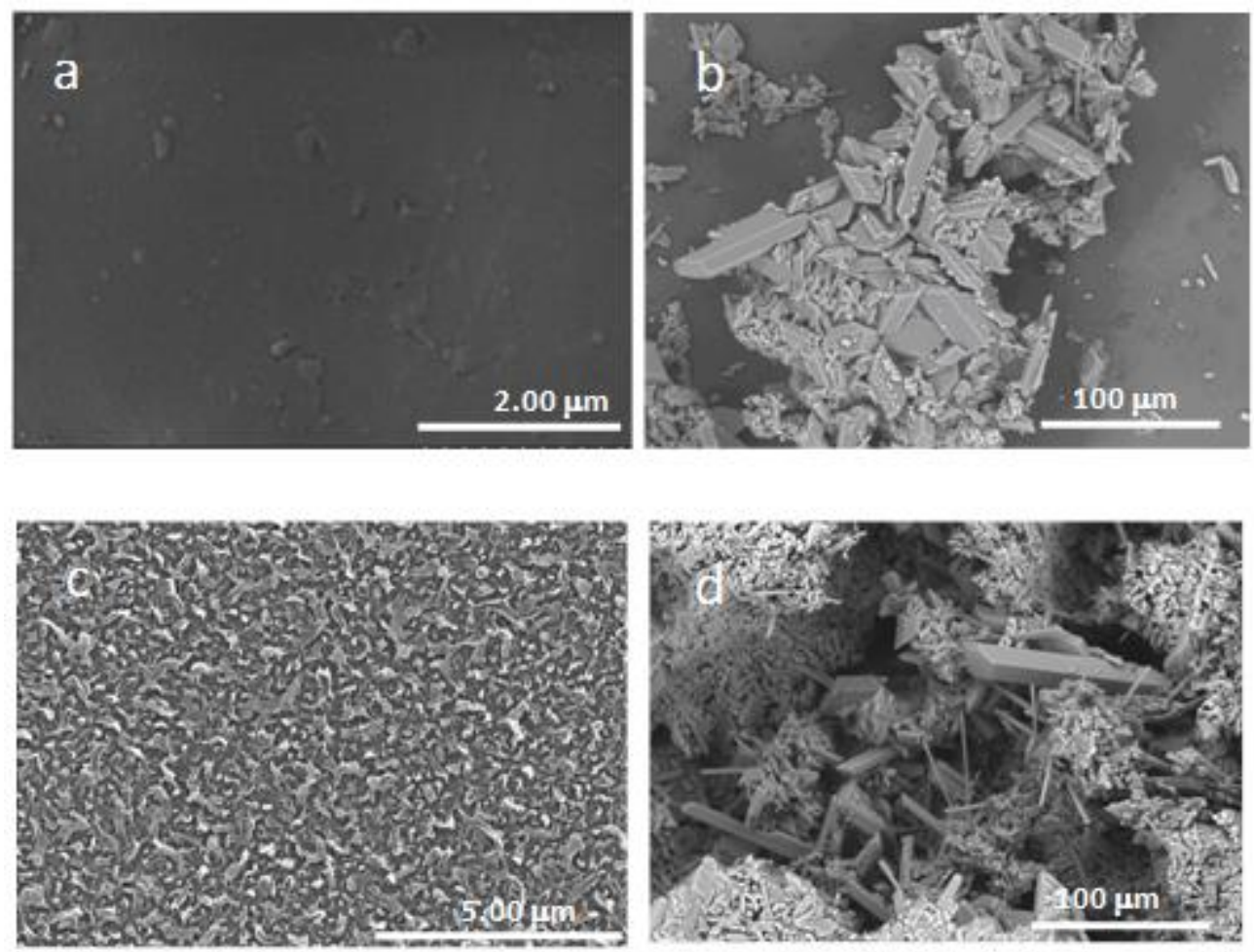

Figure 6 SEM images of the top surfaces of flat CTA and TFC membranes before (a, c) and after (b, d) concentrating UGB.

Energy dispersive X-ray spectroscopy (EDX) was adopted to analyze the elemental composition of the crystal deposits on the membrane surface. As shown in

319 Figure 7a, only $\mathrm{C}$ and $\mathrm{O}$ elements were observed on the clean CTA membrane surface as anticipated while for the scaled CTA membrane, substantial amount of $\mathrm{Mg}, \mathrm{Ca}, \mathrm{Na}$,

$321 \mathrm{Cl}$, and $\mathrm{S}$ were observed (Figure $7 \mathrm{~b}$ ). Likewise, the fresh TFC membrane showed

322 peaks for $\mathrm{C}, \mathrm{O}$, and $\mathrm{S}$ elements (Figure $7 \mathrm{c}$ ). For the fouled TFC membrane, $\mathrm{Mg}, \mathrm{Ca}$,

$323 \mathrm{Na}, \mathrm{Cl}$ and $\mathrm{S}$ were observed similar to the scaled CTA membrane. According to Table

324 1, the main components in the UGB are sodium and chloride, followed by $\mathrm{Ca}, \mathrm{Mg}$ and

$325 \mathrm{SO}_{4}{ }^{2-}$. Thus, it is evident that, the membrane fouling/scaling is mainly caused by the

326 crystallization and deposition of the inorganic components from the UGB onto the membrane surface. 

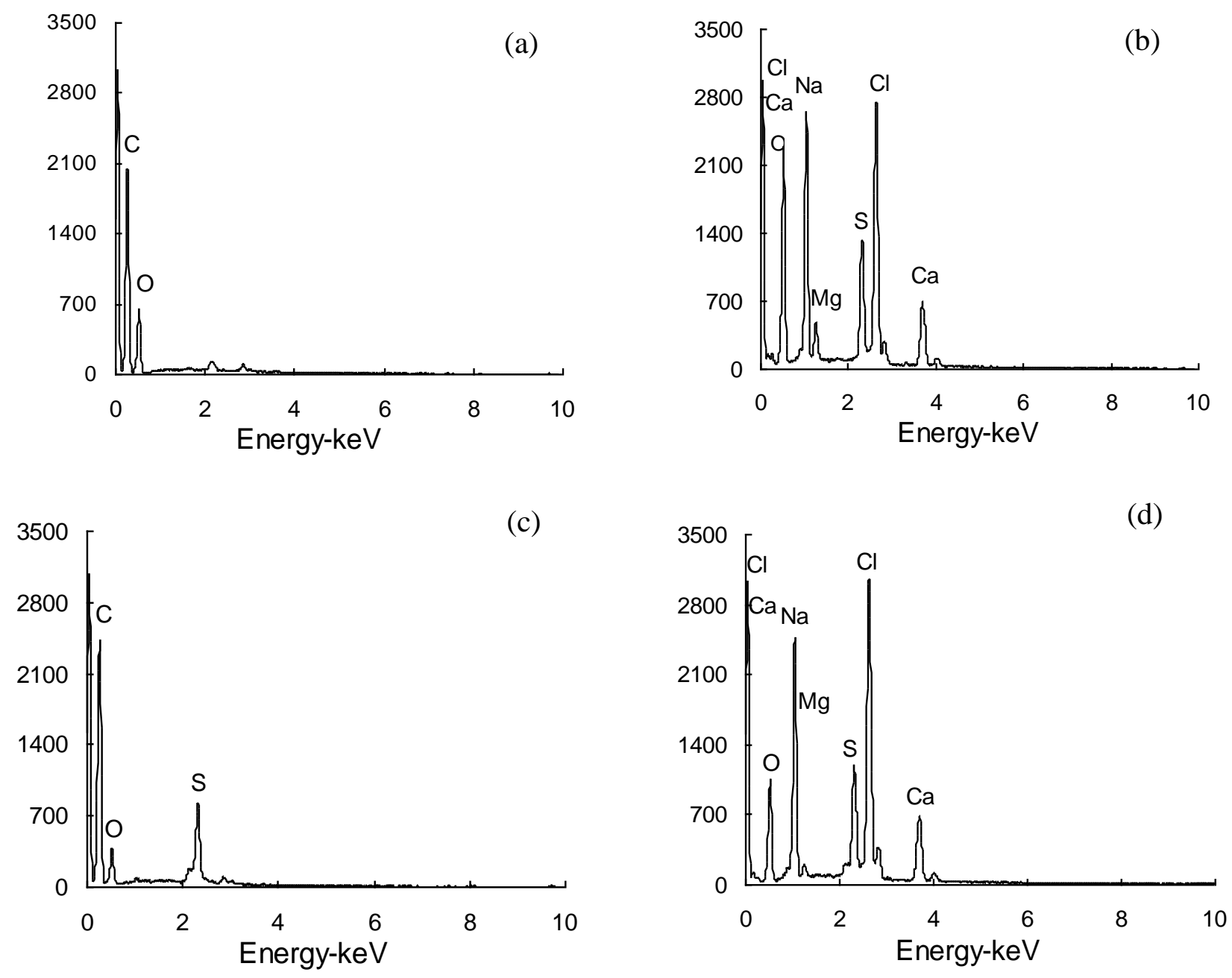

Figure 7. EDX graphs of CTA (a, b) and TFC FO (c,d) membranes before (a, c) and

330 after $(b, d)$ concentrating UGB.

The XRD patterns of the deposits, collected from the FO membrane surfaces,

333 and patterns of standard calcium sulfate $\left(\mathrm{CaSO}_{4} \cdot 2 \mathrm{H}_{2} \mathrm{O}\right)$ and sodium chloride $(\mathrm{NaCl})$,

334 are compared as shown in Figure 8. The characteristic peaks of the inorganic foulants

335 mixtures are consistent with the standard XRD patterns of both salts. Moreover, it was

336 obvious that the intensity of characteristic peaks of $\mathrm{CaSO}_{4} \cdot 2 \mathrm{H}_{2} \mathrm{O}$ was higher than that

337 of sodium chloride, indicating that the majority of the crystallites in the membrane 
scales is $\mathrm{CaSO}_{4} \cdot 2 \mathrm{H}_{2} \mathrm{O}$. This result is also logical since $\mathrm{CaSO}_{4} \cdot 2 \mathrm{H}_{2} \mathrm{O}$ has a much lower solubility than $\mathrm{NaCl}$ and is often observed as one of the major scaling component in various salt rejecting membrane processes [24].

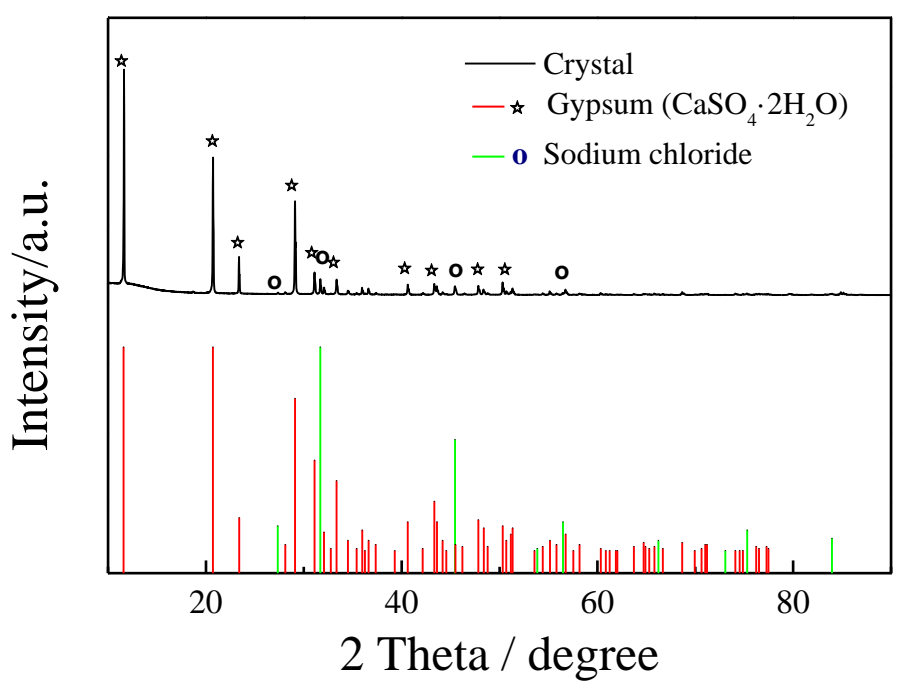

\subsection{Membrane scaling mechanism}

Spacer is often embedded in membrane modules to enhance the turbulence on the membrane surface, thereby reducing concentration polarization [26, 27]. From Fig. of UGB by FO process is examined in further paragraphs.

The mesh spacer (Figure 1) was used in FO membrane cell to enhance flow turbulence on both sides of the FO membrane. At the end of the FO experiments, the scaling pattern was observed on the membrane surface correlated well with the pattern of the mesh spacer used in the FO cell as shown in Figure $5 \mathrm{~b}$ indicating that the mesh spacer may provide a favorable condition as nucleation sites for the crystallization. As 
the UGB solution reaches the saturation concentration, nuclei tend to form and grow more rapidly. Both membrane surface and the spacer mesh likely become preferential sites for scale deposition. Particularly, the crystals formed on the spacer mesh may progressively aggregate and grow, resulting in the formation of crystals on the membrane surface, termed as surface crystallization. Surface crystallization usually occurs due to the super-saturation of scaling ions in the feed solution as permeate is extracted and the salts are rejected by the FO membrane. Nucleation and growth of inorganic scales on the membrane surface is a common issue for all the RO systems [28] and also have been reported for the FO process too [29]. As the UGB concentrating process continued, the formation of crystal covered up the whole membrane surfaces, eventually leading to a sudden flux decline (as shown in Figure 4). Thus, the presence of spacer mesh, promotes the formation of flow turbulence within the fluid channel however, it also acts as a favorable nucleation site for the scaling. Therefore, besides the membrane morphology, the contribution of spacer to scaling must be appropriately considered for the design of FO membrane module especially for the application of FO process for high salinity water such as UGB.

$$
\text { To further verify the influence of spacer to scaling for UGB concentration, FO }
$$
experiments on UGB concentration were conducted without using spacers. As shown in Fig. 9, without the spacers, the water flux of the CTA membrane did not show any transition point in contrast to our earlier results in Figure 4 where the flux transition occurred at $\mathrm{CF}$ of 1.65 . However, the flux pattern did not change significantly as compared to earlier results in Figure 3 for the TFC membrane, although the CF of the flux transition occurred this time at slightly higher $\mathrm{CF}$ of 1.92 than 1.7. After the FO 
tests, both the CTA and TFC membranes were analyzed using an optical microscope as shown in Fig. 10. The crystals were found mainly at the edge of the CTA membrane (outside the red lines as shown in Fig. 10 (A)) while there was no definite noticeable scaling pattern in the middle section of the membrane. This indicates that in the absence of mesh spacer, the scaling of the CTA membrane might occur less gradually than in the presence of mesh spacer, thus preventing the FO process from showing sudden sharp decline. For the TFC membrane however, the whole membrane surface was covered by white crystals (rectangle area shown in Fig. 10 (b)) and this likely increases the resistance to transport resulting in FO flux decline to zero soon after the transition point.

By comparing the flux patterns of CTA membrane with spacer (Fig. 4) and without spacer (Fig. 9), we have confirmed that the sudden flux decline due to scaling most probably originated from the spacer. The spacer-induced scaling for CTA membrane could be interpreted that the crystals formed in the solution might be blocked by the spacer thereby further promoting the aggregation of the crystals around the spacer (Fig. 5 b) and thus gradually covering the whole membrane surface with scaled salts. Without spacer, for a smooth CTA membrane surface, the aggregation of crystals might not be as strong as in the presence of spacer. However, the distribution of the flow velocity within the fluid channel in the FO module might not have been homogeneous, which might also have led to the aggregation of scalants at the outlet of the module as well as the corners of the cell. Since this aggregation proceeded gradually, the corresponding coverage of the CTA membrane surface was continuous and a gradual decline in FO flux was observed instead of sudden and sharp flux decline. Based on the analysis of water flux patterns and scaling distribution on 

the CTA membrane surface above, it is evident that CTA membrane scaling during UGB concentration by the FO process is derived from surface crystallization on membrane surface and also induced by the presence of spacer in FO cell.

Nevertheless, in case of TFC membrane, the rough active surface behaved differently from smooth surface CTA membrane upon scaling. Without spacer, the spacer-induced scaling was avoided. However, the rough surface tends to aggregate small crystals which further induced formation of larger aggregation of scales. Therefore, the flux transition was delayed although it still remained (Fig 4 and Fig. 9). These results indicate that TFC membrane scaling during UGB concentration by the FO process is caused by crystallization as a result of the synergistic effects of the spacers in the FO cell and rough active surface of the active layer of the TFC membrane.

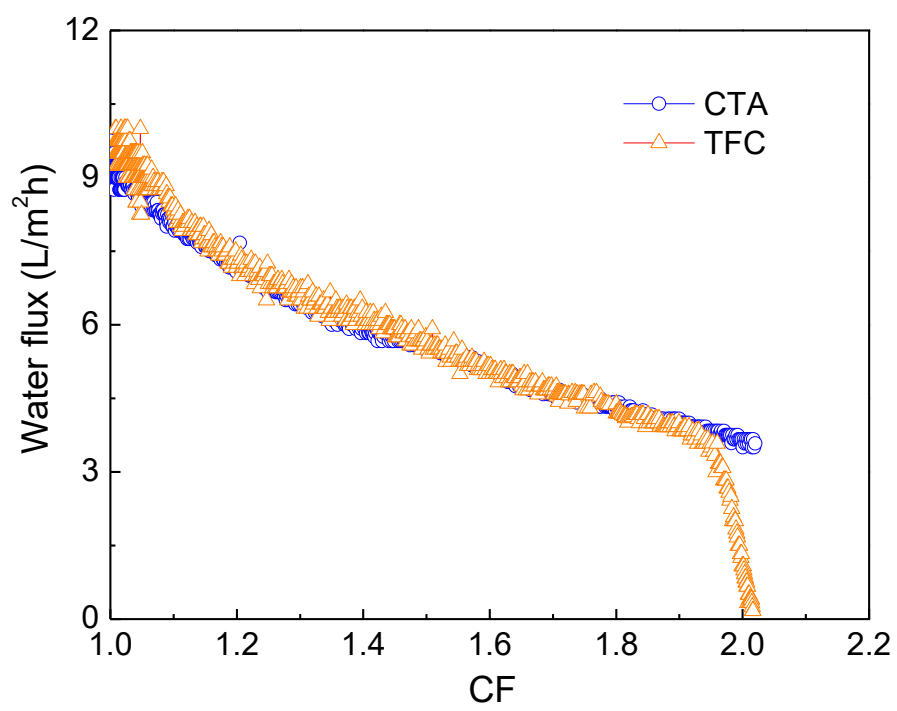

Figure 9 Water flux of UGB FO concentration using flat sheet CTA and TFC FO membranes without spacer in the FO cell (UGB and saturated sodium chloride were used as the feed and draw solution, respectively. Experiments were carried out under temperature of $20 \pm 1^{\circ} \mathrm{C}$ and flow velocities of feed and draw solution were maintained at $4.2 \mathrm{~cm} / \mathrm{s}$ ). 

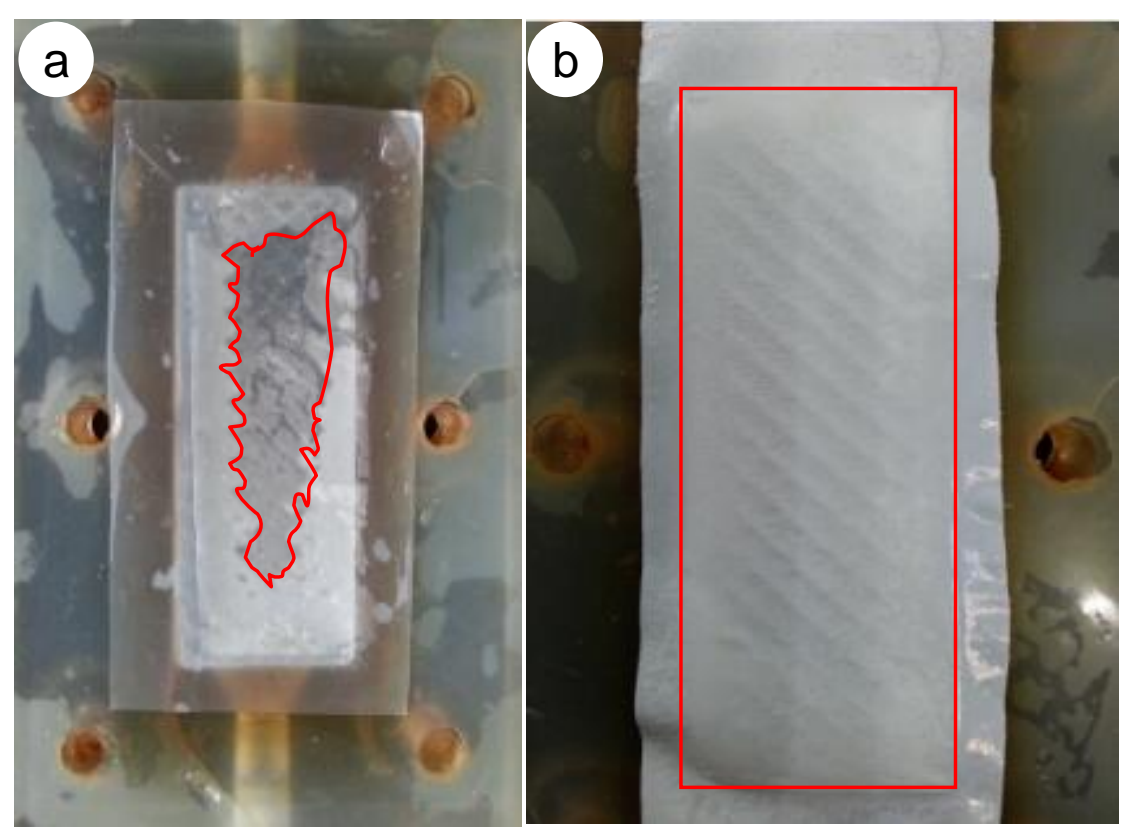

Figure 10 Optical images of top surface of CTA (a) and TFC (b) membranes after UGB FO concentration without spacer in the FO cell (UGB and saturated $\mathrm{NaCl}$ solution were used as feed and draw solution, respectively. The flow velocities of feed and draw solution were maintained at $4.2 \mathrm{~cm} / \mathrm{s}$, and the experimental temperature was controlled at $20 \pm 1^{\circ} \mathrm{C}$ )

\section{Conclusions}

The application of forward osmosis (FO) process was investigated for concentrating underground brine (UGB), based on the concept of harvesting water from brine for the recovery of valuable salts for further refining. The water flux patterns, membrane scaling propensity and performance of flat sheet TFC and CTA membranes were evaluated. Negligible flux difference was observed for the two FO membranes, in contrast to significantly different performances in the membrane characterization test. Flat sheet TFC and CTA membranes both experienced sharp flux 
declines due to inorganic scaling on the FO membrane surface due to both surface crystallization and bulk crystallization. Detail surface analysis indicates that, scaling was also induced by the spacers used in the FO cell and also due to the rough active layer surface morphology of the TFC membrane. The results from this study show that FO is feasible for the concentration of UGB however, the selection of membrane, membrane module and operation conditions needs further attention in order to avoid scaling/fouling problems especially when high salinity feed water is used for the FO process. Given the role of spacers in enhancing membrane scaling by both CTA and TFC flat sheet FO membranes, it is worthy to investigate in the future whether hollow fiber TFC FO membrane (as no spacer is used) would be more suitable for UGB concentration by FO process than the flat sheet membranes.

\section{Acknowledgements}

The authors would like to thank the partial financial support from National Natural Science Fund China (21176119), the National Key Basic Research Program of China (973 Program 2012CB932800), TMSR from Chinese Academy of Sciences (XDA02020100), Sate Key Laboratory for Modification of Chemical Fibers and Polymer Materials, Donghua University (LK1414), UTS Chancellor's Postdoctoral Research and ARC Future Fellowship (FT140101208) .

\section{References}

[1] T.Y. Cath, A.E. Childress, M. Elimelech, Forward osmosis: Principles, applications, and recent developments, J Membrane Sci, 281 (2006) 70-87. 
[2] S.F. Zhao, L.D. Zou, Effects of working temperature on separation performance, membrane scaling and cleaning in forward osmosis desalination, Desalination, 278 (2011) 157-164.

[3] W.L. Tang, H.Y. Ng, Concentration of brine by forward osmosis: Performance and influence of membrane structure, Desalination, 224 (2008) 143-153.

[4] Z.Y. Li, V. Yangali-Quintanilla, R. Valladares-Linares, Q.Y. Li, T. Zhan, G. Amy, Flux patterns and membrane fouling propensity during desalination of seawater by forward osmosis, Water Research, 46 (2012) 195-204.

[5] K.B. Petrotos, H.N. Lazarides, Osmotic concentration of liquid foods, Journal of Food Engineering, 49 (2001) 201-206.

[6] Q. Yang, K.Y. Wang, T.S. Chung, A novel dual-layer forward osmosis membrane for protein enrichment and concentration, Separation and Purification Technology, 69 (2009) 269-274.

[7] X.M. Li, B.L. Zhao, Z.W. Wang, M. Xie, J.F. Song, L.D. Nghiem, T. He, C. Yang, C.X. Li, G. Chen, Water reclamation from shale gas drilling flow-back fluid using a novel forward osmosis-vacuum membrane distillation hybrid system, Water Science and Technology, 69 (2014) 1036-1044.

[8] S. Phuntsho, H.K. Shon, S. Hong, S. Lee, S. Vigneswaran, A novel low energy fertilizer driven forward osmosis desalination for direct fertigation: Evaluating the performance of fertilizer draw solutions, J Membrane Sci, 375 (2011) 172-181.

[9] S. Loeb, Large-scale power production by pressure-retarded osmosis, using river water and sea water passing through spiral modules (vol 143, pg 115, 2002), Desalination, 150 (2002) 205-205.

[10] A. Achilli, T.Y. Cath, E.A. Marchand, A.E. Childress, The forward osmosis membrane bioreactor: A low fouling alternative to MBR processes, Desalination, 239 (2009) 10-21.

[11] L.F. Greenlee, D.F. Lawler, B.D. Freeman, B. Marrot, P. Moulin, Reverse osmosis desalination: Water sources, technology, and today's challenges, Water Research, 43 (2009) 2317-2348.

[12] C. Fritzmann, J. Lowenberg, T. Wintgens, T. Melin, State-of-the-art of reverse osmosis desalination, Desalination, 216 (2007) 1-76.

[13] N. Ghaffour, T.M. Missimer, G.L. Amy, Technical review and evaluation of the economics of water desalination: Current and future challenges for better water supply sustainability, Desalination, 309 (2013) 197-207.

[14] D.L. Shaffer, J.R. Werber, H. Jaramillo, S. Lin, M. Elimelech, Forward osmosis: Where are we now?, Desalination.

[15] D.Z. Zuguang Zou, Zhirong Tan, Ground brine resource and its exploitation in Shandong province, Geological Survey and Research, 31 (2010) 214-221.

[16] S.H. Kim, Kwak, S.Y., Suzuki, T., Positron annihilation spectroscopic evidence to demonstrate the flux-enhancement mechanism in morphology-controlled thin-film-composite (TFC) membrane, Environmental Science \& Technology, 39 (2005) 1764-1770.

[17] T.Y. Cath, M. Elimelech, J.R. McCutcheon, R.L. McGinnis, A. Achilli, D. Anastasio, A.R. Brady, A.E. Childress, I.V. Farr, N.T. Hancock, J. Lampi, L.D. Nghiem, M. Xie, N.Y. Yip, Standard Methodology for Evaluating Membrane Performance in Osmotically Driven Membrane Processes, Desalination, 312 (2013) 31-38.

[18] M.C.Y. Wong, K. Martinez, G.Z. Ramon, E.M.V. Hoek, Impacts of operating conditions and solution chemistry on osmotic membrane structure and performance, Desalination, 287 (2012) 340-349.

[19] L.S. Clesceri, Greenberg, A.E. \& Eaton, A.D. (eds), Standard Methods for the Examination of Water and Wastewater, 20th edn, American Public Health Association/American Water Works 
Association/Water Environment Federation, Washington, DC, USA, 1999.

[20] K.L. Hickenbottom, T.Y. Cath, Sustainable operation of membrane distillation for enhancement of mineral recovery from hypersaline solutions, J Membrane Sci, 454 (2014) 426-435.

[21] J.R. McCutcheon, R.L. McGinnis, M. Elimelech, Desalination by ammonia-carbon dioxide forward osmosis: Influence of draw and feed solution concentrations on process performance, J Membrane Sci, 278 (2006) 114-123.

[22] Y. Xu, X. Peng, C.Y. Tang, Q.S. Fu, S. Nie, Effect of draw solution concentration and operating conditions on forward osmosis and pressure retarded osmosis performance in a spiral wound module, $\mathrm{J}$ Membrane Sci, 348 (2010) 298-309.

[23] G. Chen, Z. Wang, L.D. Nghiem, X.-M. Li, M. Xie, B. Zhao, M. Zhang, J. Song, T. He, Treatment of shale gas drilling flowback fluids (SGDFs) by forward osmosis: Membrane fouling and mitigation, Desalination.

[24] B.X. Mi, M. Elimelech, Gypsum Scaling and Cleaning in Forward Osmosis: Measurements and Mechanisms, Environmental Science \& Technology, 44 (2010) 2022-2028.

[25] Y.L. Liu, B.X. Mi, Combined fouling of forward osmosis membranes: Synergistic foulant interaction and direct observation of fouling layer formation, J Membrane Sci, 407 (2012) 136-144.

[26] A.I. Radu, J.S. Vrouwenvelder, M.C.M. van Loosdrecht, C. Picioreanu, Effect of flow velocity, substrate concentration and hydraulic cleaning on biofouling of reverse osmosis feed channels, Chemical Engineering Journal, 188 (2012) 30-39.

[27] S.R. Suwarno, X. Chen, T.H. Chong, V.L. Puspitasari, D. McDougald, Y. Cohen, S.A. Rice, A.G. Fane, The impact of flux and spacers on biofilm development on reverse osmosis membranes, J Membrane Sci, 405-406 (2012) 219-232.

[28] A. Antony, J.H. Low, S. Gray, A.E. Childress, P. Le-Clech, G. Leslie, Scale formation and control in high pressure membrane water treatment systems: A review, J Membrane Sci, 383 (2011) 1-16.

[29] S. Phuntsho, F. Lotfi, S. Hong, D.L. Shaffer, M. Elimelech, H.K. Shon, Membrane scaling and flux decline during fertiliser-drawn forward osmosis desalination of brackish groundwater, Water Res, 57 (2014) 172-182.

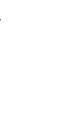

